\title{
Association of aromatase and estrogen receptor gene polymorphisms with hip fractures
}

\author{
C. Valero • J. L. Pérez-Castrillón • M. T. Zarrabeitia • \\ J. L. Hernández • M. A. Alonso • J. del Pino-Montes • \\ J. M. Olmos • J. González-Macías • J. A. Riancho
}

Received: 30 June 2007 / Accepted: 3 October 2007 / Published online: 26 October 2007

(C) International Osteoporosis Foundation and National Osteoporosis Foundation 2007

\begin{abstract}
Summary Two polymorphisms of the aromatase and estrogen receptor genes appeared to interact to influence the risk of hip fractures in women.

Introduction Allelic variants of the aromatase gene have been associated with bone mineral density and vertebral fractures. Our objective was to analyze the relationship between two polymorphisms of the aromatase and estrogen receptor genes and hip fractures.

Methods We studied 498 women with hip fractures and 356 controls. A C/G polymorphism of the aromatase gene and a
\end{abstract}

Supported by grants from Fondo de Investigaciones Sanitarias (FIS 04/ 28 and 06/34).

C. Valero · J. L. Hernández · J. M. Olmos · J. González-Macías •

J. A. Riancho $(\bowtie)$

Department of Internal Medicine, Hospital U.M. Valdecilla,

University of Cantabria,

39008 Santander, Spain

e-mail: rianchoj@unican.es

\section{J. L. Pérez-Castrillón}

Department of Internal Medicine, Hospital U. Río Hortega,

University of Valladolid,

Valladolid, Spain

M. T. Zarrabeitia

Unit of Legal Medicine, University of Cantabria,

Santander, Spain

M. A. Alonso

Department of Traumatology, Hospital U.M. Valdecilla, University of Cantabria,

Santander, Spain

J. del Pino-Montes

Department of Internal Medicine, Hospital U. Virgen de la Vega, University of Salamanca,

Salamanca, Spain
$\mathrm{T} / \mathrm{C}$ polymorphism of the estrogen receptor $\alpha$ gene were analyzed using Taqman assays. Aromatase gene expression was determined in 43 femoral neck samples by real-time RT-PCR.

Results There were no significant differences in the overall distribution of genotypes between the fracture and control groups. However, among women with a TT genotype of the estrogen receptor, the $\mathrm{CC}$ aromatase genotype was more frequent in women with fractures than in controls (39 vs. $23 \%, p=0.009$ ). Thus, women homozygous for $\mathrm{T}$ alleles of estrogen receptor and $\mathrm{C}$ alleles of aromatase were at increased risk of fracture (odds ratio $2.0 ; 95 \%$ confidence interval 1.2-3.4). The aromatase polymorphism was associated with RNA levels in bone tissue, which were three times lower in samples with a CC genotype $(p=0.009)$. Conclusions These common polymorphisms of the aromatase and estrogen receptor genes appear to interact, influencing the risk of hip fractures in women.

Keywords Aromatase $\cdot$ Estrogen receptor $\cdot$ Hip fractures . Osteoporosis $\cdot$ Polymorphisms

\section{Introduction}

Genetic factors are known to have an important influence on bone mass and the risk of developing osteoporosis [1-3]. Given the role of estrogen in bone homeostasis, genes related to estrogen metabolism are likely candidates to contribute to such hereditary influence. There are two types of estrogen receptors, $\alpha$ and $\beta$, encoded by genes situated in chromosomes 6 and 14 respectively. Type $\alpha$ receptors are usually considered the most important in mediating the effects of estrogen effects on bone $[4,5]$. The main source of estrogen in postmenopausal women is the aromatization of androgenic 
precursors, a reaction catalyzed by aromatase, the product of the CYP19A1 gene [6]. In humans the gene is expressed not only in the gonads, but also in other tissues, including the adipose tissue and bone. The influence of aromatase-derived estrogen on the skeleton is revealed by the reduction of bone mineral density (BMD) in postmenopausal women treated with aromatase inhibitors [7].

The CYP19A1 gene is located on chromosome 15q21 and spans about $120 \mathrm{~kb}$. It has a $30-\mathrm{kb}$ coding region and a long $5^{\prime}$ region, spanning about $90 \mathrm{~kb}$. This $5^{\prime}$ region contains regulatory sequences and several variants of the first exon, whose transcription is driven by different tissuespecific promoters. Several investigators have reported an association between some common polymorphisms of the aromatase gene and BMD [8-10]. We have previously shown that a gene-gene interaction between aromatase and estrogen receptor $\alpha$ appears to influence BMD in postmenopausal women [11]. Since hip fractures are the most devastating consequence of osteoporosis, the objective of this study was to determine the possible relationship between those polymorphisms in the aromatase and estrogen receptor genes and hip fractures.

\section{Materials and methods}

\section{Study participants}

We studied 854 postmenopausal women, 498 with hip fractures and 356 controls. Consecutive women admitted to hospital because of a hip fracture were included, unless they fitted the exclusion criteria. We excluded women with fractures due to high-impact trauma (such as traffic accidents and falls from a height), diseases causing secondary osteoporosis (cancer, rheumatoid arthritis, malabsorption, severe systemic diseases, etc.) or taking drugs known to have a deleterious effect on bone metabolism (corticosteroids, anticonvulsants). Control women aged over 60, without known fractures after the menopause and not receiving anti-osteoporotic therapy were recruited by oral and written announcements from various sources to prevent a preferential selection bias (hospital workers, civic associations, religious groups, and geriatric residences). All participants were interviewed by one of the investigators to check the absence of exclusion criteria. Subjects with non-Spanish ancestry were excluded. Calcium intake from dairy products was estimated by a questionnaire [12]. Recreational physical activity was graded semiquantitatively, and women were considered to exercise if they walked more than $3 \mathrm{~km}$ daily or were engaged in other sport activities. Alcohol intake was defined as a daily intake of more than $10 \mathrm{~g}$. Women were regarded as smokers if they had a present or past history of smoking at least 5 cigarettes per day for a minimum of 5 years. Age at menopause was established by recalling the last menstruation. The study protocol was approved by the Institutional Committee of Ethics in Clinical Research, and informed consent was obtained from study participants or their representatives.

\section{Genotyping}

DNA was isolated from the peripheral blood or from buccal swabs with a commercial kit (Qiagen, Hilden, Germany), following the manufacturer's instructions. A C/G SNP located in the I.2 region of the aromatase gene (rs1062033) and a T/C SNP located in the first intron of the estrogen receptor (rs2234693) were typed using Taqman assays (Applied Biosystems), as previously reported [10, 11].

\section{Gene expression}

Bone samples were obtained from the femoral neck during hip replacement procedures for hip fractures in 43 patients. In brief, small fragments of trabecular bone were extensively washed with PBS, snap-frozen in liquid nitrogen and stored at $-70^{\circ} \mathrm{C}$. Unthawed fragments were mashed and pulverized with a tissue homogenizer into Trizol (Invitrogen) to extract RNA. RNA integrity was checked by gel electrophoresis and the concentration measured by absorptiometry. Aliquots of RNA (about $1 \mu \mathrm{g}$ ) were reversetranscribed with the Superscript III kit (Invitrogen), using random hexamers as primers. In negative control reactions reverse transcriptase was omitted. After RT-PCR, aromatase gene expression was determined by real-time PCR in an ABI7300 apparatus (Applied Biosystems). The reactions were performed in triplicate in 96-well plates containing aliquots of the cDNA obtained by reverse transcription, $5 \mu \mathrm{l}$ of universal PCR master mix, and primers and probe complementary to the I.2 exon sequence (Taqman Gene Expression Assays, Applied Biosystems).

The cycle threshold $(\mathrm{Ct})$ was determined. This represents the cycle at which a significant increase in fluorescence is first detected and is inversely related to the amount of target cDNA in the starting material. In samples with nondetectable amplification of aromatase, the Ct was arbitrarily set at 44. The results were normalized to TBP (TATA box binding protein) expression analyzed in the same reaction plate. Control samples of reverse-transcribed reference human RNA (Stratagene, La Jolla, CA, USA) were also included. The relative RNA levels were calculated using the formula $2^{\Delta \mathrm{Ct} 1-\Delta \mathrm{Ct} 2}$, where $\Delta \mathrm{Ct} 1$ is the difference between the control cDNA $\mathrm{Ct}$ and the sample cDNA $\mathrm{Ct}$ when the target gene (aromatase) is amplified, and $\Delta \mathrm{Ct} 2$ is the difference between control cDNA Ct and the sample cDNA $\mathrm{Ct}$ when the control gene (TBP) is amplified. 
Table 1 Characteristics of the women studied

\begin{tabular}{llll}
\hline & Control & Hip fracture & $p$ \\
\hline Age, years & $78 \pm 9$ & $83 \pm 8$ & $<0.001$ \\
Age at menopause, years & $50 \pm 5$ & $49 \pm 4$ & 0.3 \\
Calcium intake, mg/day & $649 \pm 337$ & $586 \pm 332$ & 0.01 \\
Exercise, \% & 17 & 4 & $<0.001$ \\
Tobacco, \% & 6 & 2 & 0.02 \\
Alcohol, \% & 4 & 2 & 0.07 \\
Prior stroke or TIA, \% & 6 & 8 & 0.3 \\
\hline
\end{tabular}

\section{Statistical analysis}

The Hardy-Weinberg equilibrium was tested with HWSIM software http://krunch.med.yale.edu/hwsim/hwsim.doc). The characteristics of the control and fracture groups were compared by means of the $t$ test, the Mann-Whitney $U$ test or the $\chi^{2}$ test. Differences in genotype distribution were analyzed using the $\chi^{2}$ test. The association between genotypes and fractures was studied using logistic regression analysis. The non-parametric Jonckheere-Terpstra test for ordered categories and the $U$ test were used to analyze the differences in aromatase gene expression between participants with different genotypes. SPSS software was used (SPSS, Chicago, IL, USA).

\section{Results}

Association between genotypes and fractures

The main characteristics of the two groups are shown in Table 1. As expected, women with fractures were slightly older and had more comorbid conditions than control women.

There was no evidence of departure from the HardyWeinberg equilibrium ( $p=0.31$ and 0.27 , for the aromatase and the estrogen receptor genes respectively). The distribution of genotypes in the control and fracture groups is shown in Table 2. Genotype frequencies were similarly distributed in both groups. According to the results of previous studies, we combined aromatase and estrogen receptor genotypes into two groups $(\mathrm{CC}$ and $\mathrm{CG}$ $+\mathrm{GG}$ for the aromatase, and $\mathrm{TT}$ and $\mathrm{TC}+\mathrm{CC}$ for the estrogen receptors) and performed a logistic regression analysis. It revealed a significant gene-gene interaction ( $p=0.007$ in unadjusted models and 0.004 in age-adjusted models). In the group of women bearing TC/CC alleles of the estrogen receptor there was no association between aromatase and fractures. However, among women with TT alleles of the estrogen receptor, the $\mathrm{CC}$ aromatase genotype was significantly more common in women with fractures than in controls ( 39 vs. $23 \%, p=0.009$ ). Thus, the unadjusted odds ratio was 2.1 (95\% confidence interval 1.2-3.8) and the age-adjusted odds ratio was 2.4 (95\% confidence interval $1.3-4.4, p=0.005$ ). There was no evidence of an interaction of age with the association between aromatase genotype and hip fracture $(p=0.41)$, and similar odds ratios were found in women under 80 years of age $(2.6,95 \%$ confidence interval $1.0-6.9)$ and in those aged over $80(2.5,95 \%$ confidence interval $1.1-$ 5.6). Adjustment by other potential confounding factors (calcium intake, tobacco or alcohol consumption, comorbidities) did not significantly change the estimated odds ratio (not shown).

Table 2 Distribution of aromatase and estrogen receptor genotypes ( $n$ and \%)

\begin{tabular}{|c|c|c|c|}
\hline Genotype & Control group & Fracture group & All participants \\
\hline \multicolumn{4}{|c|}{ Aromatase } \\
\hline $\mathrm{CC}$ & $111(31)$ & $166(33)$ & $277(32)$ \\
\hline $\mathrm{CG}$ & $182(51)$ & $253(51)$ & $435(51)$ \\
\hline GG & $63(17)$ & $79(16)$ & $142(17)$ \\
\hline$p$ & 0.70 & & \\
\hline \multicolumn{4}{|c|}{ Estrogen receptor } \\
\hline $\mathrm{TT}$ & $97(27)$ & $153(31)$ & $250(29)$ \\
\hline $\mathrm{TC}$ & $169(47)$ & $236(47)$ & $405(47)$ \\
\hline $\mathrm{CC}$ & $90(25)$ & $109(22)$ & $199(23)$ \\
\hline$p$ & 0.39 & & \\
\hline
\end{tabular}


Table 3 Distribution of aromatase genotypes in the control and fracture groups according to the estrogen receptor genotype ( $n$ and \%)

\begin{tabular}{lllll}
\hline Aromatase & Estrogen receptor & Hip fractures & Controls & OR (CI) \\
\hline CG/GG & TC/CC & $238(48)$ & $170(48)$ & $1.0($ reference $)$ \\
CG/GG & TT & $94(19)$ & $75(21)$ & $0.9(0.6-1.3)$ \\
CC & TC/CC & $107(21)$ & $89(25)$ & $0.9(1.6-1.2)$ \\
CC & TT & $59(12)$ & $22(6)$ & $1.9(1.1-3.2)$ \\
All & All & $498(100)$ & $356(100)$ &
\end{tabular}

In Table 3 we show the distribution of the women across the four groups defined by aromatase and estrogen receptor genotypes. The odds ratio for fractures in women with the CC aromatase genotype and the TT estrogen receptor genotype was 2.0 (95\% CI 1.2-3.4), in comparison with women with any other genotype, and 1.9 (95\% CI 1.1-3.2) in comparison with women with the $\mathrm{CG} / \mathrm{GG}$ aromatase genotype and the $\mathrm{TC} / \mathrm{CC}$ estrogen receptor genotype.

\section{Aromatase gene expression}

Aromatase transcripts containing the I.2 exon sequence were detected in bone samples from 37 out of 43 patients. Aromatase alleles were associated with gene expression. As shown in Fig. 1, aromatase transcripts were significantly less abundant in samples taken from women with the $\mathrm{CC}$ genotype than in samples from women with other genotypes. No significant differences existed between the $\mathrm{CG}$ and GG genotypes.

\section{Discussion}

The association between estrogen receptor gene polymorphisms and osteoporosis has been extensively studied. The rs2234693 SNP analyzed here has been a subject of particular interest. In the literature it has been commonly referred to as the PvuII polymorphism, as many investigators characterized it by using the PvuII restriction enzyme [13-16]. In this study we did not find significant differences in estrogen receptor allele or genotype distribution between hip fracture patients and controls. Similar negative results have been reported by other investigators [17-20].

To our knowledge this is the first published study about the relationship between aromatase gene polymorphisms and hip fractures. Our results suggest that this polymorphism of the aromatase gene, previously shown to be associated with BMD, is associated with hip fractures in women bearing a certain genotype of the estrogen receptor.

We did not find evidence of a significant association between either gene polymorphism and hip fractures when they were analyzed separately, but the association was revealed in the combined analysis. This is consistent with a small effect of each gene variant, which can only be demonstrated in the joint analysis, and represents an example of epistasis (gene-gene interaction) between two genes involved in estrogen metabolism. Specifically, those genes are related to estrogen synthesis and estrogen response respectively. Thus, such interaction seems plausible from a biological point of view. Furthermore, these findings fit the contention that these genes contribute to explain the genetic component of osteoporosis. In fact, we and others have demonstrated that several polymorphisms of the aromatase gene are associated with differences in BMD, estrogen circulating levels in postmenopausal women, and osteoporotic vertebral fractures [8-10, 12, 21-26].

These polymorphisms are situated in non-coding regions. Therefore, their association with osteoporosis must be due to differences in gene expression, not to changes in protein sequences. In fact, it has been suggested that the rs2234693 SNP in intron 1 of the estrogen receptor might modulate gene transcription. The $\mathrm{C}$ allele, but not the $\mathrm{T}$ allele, contains a functional Myb binding site and transfection experiments with luciferase reporters showed a 4-fold higher transcription rate in cells incorporating constructs with the $\mathrm{C}$ allele, in comparison with those transfected with constructs bearing the T allele [27]. These results would suggest that cells with $\mathrm{T}$ alleles express fewer estrogen receptor molecules, which could render them more sensi-

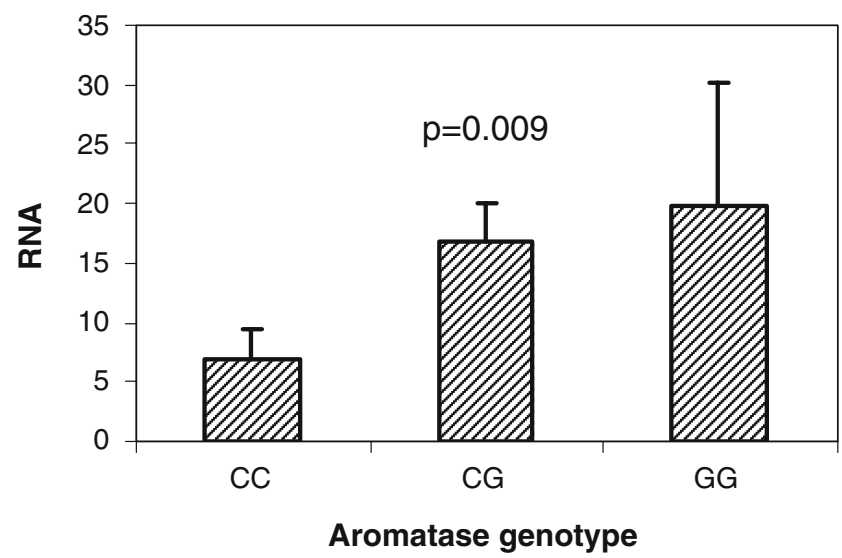

Fig. 1 Aromatase gene expression in bone tissue according to genotype. RNA levels of I.2-specific transcripts (arbitrary units, mean, and SEM) 
tive to a reduced supply of estrogen. Although merely speculative, this mechanism would be consistent with our findings showing that different genotypes of the estrogensynthesizing aromatase are associated with BMD in women with $\mathrm{T}$ alleles, but not in those with $\mathrm{C}$ alleles [11].

On the other hand, we provide evidence that aromatase alleles are associated with differences in gene expression. Aromatase transcripts were less abundant in bone samples from women with CC genotypes than in women with CG or GG genotypes. These results fit with the association data, for the CC genotype was related to a higher risk of hip fractures. They also agree with our previous data showing a relationship between aromatase genotype and gene expression in the adipose tissue [21]. Therefore, we hypothesize that women with TT alleles of the estrogen receptor are more sensitive to small changes in estrogen availability, such as those determined by aromatase allelic variants. Thus, women with unfavorable variants of both genes are at increased risk of hip fractures. The molecular mechanism involved in the differences in aromatase RNA levels across different genotypes has not been elucidated, but it is likely to depend on differences in the ability to bind transcription factors, which in turn results in differential allelic expression [21]. Whatever the mechanism might be, women with $\mathrm{C}$ alleles appear to express less aromatase at the tissue level and are therefore likely to have less bioavailable estradiol after the menopause, which in the long term will have a deleterious influence on the bone mass and result in a higher risk of fractures. Only in homozygotes for the C allele, but not in the heterozygotes, did we observe statistically significant differences in aromatase gene expression and hip fracture risk. Therefore, our data fitted a recessive genetic model better.

This study has several limitations. Some of them are inherent to a case-control design and the difficulty in recruiting elderly control participants. As a consequence, there was some imbalance between fracture and controls regarding age and other characteristics. It may theoretically introduce some bias, but the association between gene variants and fracture risk did not change when those differences were taken into consideration in multivariate models or age-stratified analysis. Moreover, since the control participants were somewhat younger than the fracture patients, it might be expected that such potential bias would tend to change the results toward the null hypothesis (i.e., some control women might perhaps suffer fractures in the future), thus making our data conservative estimates of the association between genotypes and fractures. Nevertheless, the results should ideally be confirmed in longitudinal studies to strengthen the conclusions. Also, due to the lack of complete anthropometric data in fracture patients, we were unable to adjust the results for certain factors that may have an important influence on bone homeostasis, such as body weight. We have previously shown an association between aromatase and estrogen receptor gene polymorphisms and BMD [26, 28]. Since we did not have BMD data in hip fracture patients, we were not able to establish to what extent the association between the aromatase genotype and hip fractures was dependent on differences in BMD.

It has been estimated that genetic factors explain about $50-80 \%$ of BMD variance and many studies have addressed the association between candidate genes and BMD. Although more difficult to demonstrate because of the occurrence of multiple potential confounding factors in the elderly population, hip fractures also have a genetic component, as revealed by the increased risk in daughters of patients who have suffered fractures [29, 30]. In a recent study, Michaelsson et al. estimated that the global ageadjusted heritability of hip fractures was $48 \%$, but this decreased with advancing age [31]. In this study we show that some allelic variants of the aromatase gene interact with the estrogen receptor gene to explain, in part, that genetic influence on hip fracture risk.

\section{References}

1. Ralston SH, de Crombrugghe B (2006) Genetic regulation of bone mass and susceptibility to osteoporosis. Genes Dev 20:2492-2506

2. Baldock PA, Eisman JA (2004) Genetic determinants of bone mass. Curr Opin Rheumatol 16:450-456

3. Peacock M, Turner CH, Econs MJ, Foroud T (2002) Genetics of osteoporosis. Endocr Rev 23:303-326

4. Riggs BL, Khosla S, Melton LJ III (2002) Sex steroids and the construction and conservation of adult skeleton. Endocr Rev 23:279-302

5. Syed FS, Khosla S (2005) Mechanisms of sex steroid effects on bone. Biochem Biophys Res Commun 328:688-696

6. Simpson ER (2000) Role of aromatase in sex steroid action. J Mol Endocrinol 25:1549-1556

7. McCloskey E (2006) Effects of third-generation aromatase inhibitors on bone. Eur J Cancer 42:1044-1051

8. Masi L, Becherini L, Gennari L et al (2001) Polymorphism of the aromatase gene in postmenopausal Italian women: distribution and correlation with bone mass and fracture risk. J Clin Endocrinol Metab 86:2263-2269

9. Somner J, McLellan S, Cheung J et al (2004) Polymorphisms in the P450 c17(17-hydroxylase/17,20-lyase) and P450 c19 (aromatase) genes: association with serum sex steroid concentrations and bone mineral density in postmenopausal women. J Clin Endocrinol Metab 89:344-351

10. Zarrabeitia MT, Hernandez JL, Valero C et al (2004) A common polymorphism in the 5 -untranslated region of the aromatase gene influences bone mass and fracture risk. Eur J Endocrinol 150:699-704

11. Riancho JA, Zarrabeitia MT, Valero C, Sanudo C, Mijares V, Gonzalez-Macias J (2006) A gene-to-gene interaction between aromatase and estrogen receptors influences bone mineral density. Eur J Endocrinol 155:53-59

12. Riancho JA, Zarrabeitia MT, Valero C et al (2005) Aromatase gene and osteoporosis: relationship of ten polymorphic loci with bone mineral density. Bone 36:917-925 
13. Choi JY, Shin A, Park SK et al (2005) Genetic polymorphisms of OPG, RANK, and ESR1 and bone mineral density in Korean postmenopausal women. Calcif Tissue Int 77:152-159

14. Gennari L, Merlotti D, De Paola V et al (2005) Estrogen receptor gene polymorphisms and the genetics of osteoporosis: a HuGE review. Am J Epidemiol 161:307-320

15. Kobayashi N, Fujino T, Shirogane T et al (2002) Estrogen receptor alpha polymorphism as a genetic marker for bone loss, vertebral fractures and susceptibility to estrogen. Maturitas 41:193-201

16. Nam HS, Shin MH, Kweon SS et al (2005) Association of estrogen receptor-alpha gene polymorphisms with bone mineral density in postmenopausal Korean women. J Bone Miner Metab 23:84-89

17. Kjaergaard AD, Ellervik C, Tybjaerg-Hansen A (2007) Estrogen receptor alpha polymorphism and risk of cardiovascular disease, cancer, and hip fracture: cross-sectional, cohort, and case-control studies and a meta-analysis. Circulation 115:861-871

18. Aerssens J, Dequeker J, Peeters J, Breemans S, Broos P, Boonen S (2000) Polymorphisms of the VDR, ER and COLIA1 genes and osteoporotic hip fracture in elderly postmenopausal women. Osteoporos Int 11:583-591

19. Ioannidis JPA, Ralston SH, Bennett ST, Brandi ML, Grinberg D, Karassa FB et al (2004) Differential genetics effects of ESR1 gene polymorphisms on osteoporosis outcomes. JAMA 292:2105-2114

20. Ioannidis JPA, Stavrou I, Trikalinos TA et al (2002) Association of polymorphisms of the estrogen receptor alpha gene with bone mineral density and fracture risk in women: a meta-analysis. J Bone Miner Res 17:2048-2060

21. Riancho JA, Valero C, Naranjo A, Morales DJ, Sanudo C, Zarrabeitia MT (2007) Identification of an aromatase haplotype that is associated with gene expression and postmenopausal osteoporosis. J Clin Endocrinol Metab 92:660-665
22. Haiman CA, Dossus L, Setiawan VW et al (2007) Genetic variation at the CYP19A1 locus predicts circulating estrogen levels but not breast cancer risk in postmenopausal women. Cancer Res 67:1893-1897

23. Olson SH, Bandera EV, Orlow I (2007) Variants in estrogen biosynthesis genes, sex steroid hormone levels, and endometrial cancer: a HuGE review. Am J Epidemiol 165:235-245

24. Dick IM, Devine A, Prince RL (2005) Association of an aromatase TTTA repeat polymorphism with circulating estrogen, bone structure, and biochemistry in older women. Am J Physiol Endocrinol Metab 288:E989-E995

25. Xiong DH, Zhao LJ, Xiao P et al (2006) Robust and comprehensive analysis of 20 osteoporosis candidate genes by very high-density single-nucleotide polymorphism screen among 405 white nuclear families identified significant association and gene-gene interaction. J Bone Miner Res 21:1678-1695

26. Riancho JA (2007) Polymorphisms in the CYP19 gene that influence bone mineral density. Pharmacogenomics 8:339-352

27. Herrington DM, Howard TD, Brosnihan KB et al (2002) Common estrogen receptor polymorphism augments effects of hormone replacement therapy on E-selectin but not C-reactive protein. Circulation 105:1879-1882

28. Acha O, Hernandez JL, Penado S, Cano M, Riancho JA (2003) Factores de riesgo de ictus en pacientes de diferentes edades. Rev Clin Esp 203:189-192

29. Cummings SR, Nevitt MC, Browner WS et al (1995) Risk factors for hip fracture in white women. N Engl J Med 332:767-773

30. Kanis JA, Johansson H, Oden A et al (2004) A family history of fracture and fracture risk: a meta-analysis. Bone 35:1029-1037

31. Michaelsson K, Melhus H, Ferm H, Ahlbom A, Pedersen NL (2005) Genetic liability to fractures in the elderly. Arch Intern Med 165:1825-1830 